\title{
Age of red blood cells and outcome in acute kidney injury
}

\author{
Kirsi-Maija Kaukonen ${ }^{1,2^{*}}$, Suvi T Vaara ${ }^{2}$, Ville Pettilä ${ }^{2,3}$, Rinaldo Bellomo ${ }^{1}$, Jarno Tuimala ${ }^{4}$, David J Cooper ${ }^{1}$, \\ Tom Krusius ${ }^{4}$, Anne Kuitunen ${ }^{5}$, Matti Reinikainen ${ }^{6}$, Juha Koskenkari ${ }^{7}$, Ari Uusaro ${ }^{8}$ and The FINNAKI study group
}

\begin{abstract}
Introduction: Transfusion of red blood cells (RBCs) and, in particular, older RBCs has been associated with increased short-term mortality in critically ill patients. We evaluated the association between age of transfused RBCs and acute kidney injury (AKI), hospital, and 90-day mortality in critically ill patients.
\end{abstract}

Methods: We conducted a prospective, observational, predefined sub-study within the FINNish Acute Kidney Injury (FINNAKI) study. This study included all elective ICU admissions with expected ICU stay of more than 24 hours and all emergency admissions from September to November 2011. To study the age of RBCs, we classified transfused patients into quartiles according to the age of oldest transfused RBC unit in the ICU. AKI was defined according to KDIGO (Kidney Disease: Improving Global Outcomes) criteria.

Results: Out of 1798 patients, 652 received at least one RBC unit. The median [interquartile range] age of the oldest RBC unit transfused was 12 [11-13] days in the freshest quartile and 21 [17-27] days in the quartiles 2 to 4 . On logistic regression, $\mathrm{RBC}$ age was not associated with the development of KDIGO stage 3 AKI. Patients in the quartile of freshest RBCs had lower crude hospital and 90-day mortality rates compared to those in the quartiles of older blood. After adjustments, older RBC age was associated with significantly increased risk for hospital mortality. Age, Simplified Acute Physiology Score II (SAPS II)-score without age points, maximum Sequental Organ Failure Assessment (SOFA) score and the total number of transfused RBC units were independently associated with 90-day mortality.

Conclusions: The age of transfused RBC units was independently associated with hospital mortality but not with 90-day mortality or KDIGO stage 3 AKI. The number of transfused RBC units was an independent risk factor for 90-day mortality.

\section{Introduction}

Critically ill patients are frequently transfused during their stay in ICU. Around 40\% (37 to 44\%) of patients receive at least one red blood cell (RBC)-unit transfusion, the mean being 4.6 units per patient during their ICU stay [1,2]. Patients receive transfusions early after ICU admission. For example, 75\% of transfused patients receive their first $\mathrm{RBC}$ transfusion by day 3 [2]. In general, liberal blood transfusion practice does not appear beneficial in critically ill patients, with the possible

\footnotetext{
* Correspondence: maija.kaukonen@monash.edu

${ }^{1}$ ANZIC Research Centre, Department of Epidemiology and Preventative Medicine, School of Public Health \& Preventive Medicine, Monash University, 99 Commercial Road, Melbourne, VIC 3004, Australia

${ }^{2}$ Intensive Care Unit, Helsinki University Central Hospital, Helsinki, Finland Full list of author information is available at the end of the article
}

exception of those patients with acute myocardial ischemia [3] or severe sepsis and septic shock $[4,5]$.

$\mathrm{RBC}$ units undergo changes over time, including several biochemical changes in both RBCs themselves and within the preservative medium [6]. The presence of this storage lesion in $\mathrm{RBC}$ units has raised concern for the benefit and safety of $\mathrm{RBC}$ transfusions, especially if older RBC units are used. A recent meta-analysis including more than 400,000 patients concluded that in many patient groups including critically ill, cardiac surgery, trauma and pediatric patient populations, the use of older stored blood is potentially associated with a significantly increased risk of death [7]. The majority of the studies in this meta-analysis, however, were retrospective or observational. In addition, three small randomized, controlled trials (RCTs) have shown inconclusive results

\section{() Biomed Central}


[8-10]. Finally, a recent large RCT in premature infants found that fresher blood (less than 7 days old) did not reduce mortality or morbidity compared to standardof-care RBCs [11].

The observational studies included in the metaanalysis of Wang et al. reported only short-term mortality (in-hospital, 7-, 28-, and 30-day) except for one study in colorectal cancer patients [7]. The association of the age of RBC transfusions with acute kidney injury (AKI) has not been reported. Thus, the association of age of RBCs with AKI or with long-term mortality in a general ICU population has not been reported so far.

Accordingly, we conducted a prospective observational study as a part of the FINNish Acute Kidney Injury (FINNAKI) study in critically ill patients to evaluate the possible association of the age of RBCs with AKI and with hospital and 90-day mortality. FINNAKI was a prospective study evaluating the incidence, risk factors and 90-day mortality of AKI in unselected critically ill patients.

\section{Materials and methods \\ Data}

We conducted a predefined sub-study of the previously published FINNAKI study [12]. FINNAKI was a prospective, observational study comprising 2,901 critically ill patients admitted to 17 Finnish ICUs between 1 September 2011 and 1 February 2012. The patient population of this sub-study included all FINNAKI patients between 1 September 2011 and 30 November 2011.

The Ethics Committee of the Department of Surgery in Helsinki University Hospital gave approval for this study and the use of deferred consent. Signed, informed consent was obtained from the patient or proxy as soon as possible after ICU admission. If informed consent could not be obtained, the Finnish National Institute of Health and Welfare approved the data collection for study purposes from deceased patients.

\section{Study patients}

The study inclusion criteria were: 1) all emergency ICU admissions, and 2) all elective patients with an expected ICU stay of $>24$ hours. The exclusion criteria were: 1 ) age less than 18 years, 2) readmission after receiving renal replacement therapy (RRT) during a previous admission, 3) elective ICU admission for less than 24 hours if discharged alive, 4) chronic dialysis, 5) organ donation, 6) no permanent residency in Finland or insufficient language skills, 7) transferred patients included in the study in previous ICU, and 8) intermediate care patients.

\section{Red blood cell products}

In Finland, all RBC units are provided by the Finnish Red Cross Blood Service. RBC products are prepared from anticoagulated whole blood by the buffy coat method.
After addition of saline-adenine-glucose-mannitol (SAGM) solution RBCs are leukodepleted by filtration. RBC products comply with European Union directives and Council of Europe standard [13]. In RBC product quality control $(n=2,904$, year 2011), the mean amount of hemoglobin was $49.8 \mathrm{~g} / \mathrm{unit}$ (CI 95\% 40.6, $59.0 \mathrm{~g} / \mathrm{unit}$ ) and the number of residual leukocytes $0.03 \times 10^{6} /$ unit (CI $95 \% 0.00,0.13 \times 10^{6} /$ unit). The shelf life of RBC products is 35 days.

\section{Data collection}

The Finnish Intensive Care Consortium prospective database (Tieto Ltd, Helsinki, Finland) served as the source for routine ICU data. The study-specific expansion of the database included study case report forms and calculation of KDIGO (Kidney Disease: Improving Global Outcomes) stage for each patient, continuously based on every measured hourly urine output and plasma creatinine. The daily case report forms were collected from ICU admission to day 5 in the ICU. The data collection consisted of AKI and AKI risk factors, including severe sepsis, using the definition of the American College of Chest Physicians/Society of Critical Care Medicine (ACCP/SCCM) [14]. Each patient was included into the study only once. For readmitted patients, only the admission with the oldest RBCs transfused was included in the analysis. Nine randomly chosen study sites were monitored for the reliability of the data collection with a structured monitoring plan. The dates and donation numbers of all RBC units transfused to study patients during their ICU stay were obtained directly from the participating ICUs. The Finnish Red Cross Blood Services provided information on RBC product details including donation and expiry dates. We obtained data on 90-day mortality from the Finnish Population Register Center.

\section{Definitions}

AKI was defined according to the KDIGO criteria [15]. Renal non-recovery was defined as dependence on RRT at day 90 [16]. The quartiles of transfused patients were defined by calculating the age of all RBCs transfused to the patient. The oldest RBC unit was chosen as the index unit to allocate the patient to the RBC age quartiles [17]. The lowest quartile (Q1) denotes patients with the freshest oldest RBC unit. Q2, Q3, and Q4 denote patients in the second, third and fourth quartiles, respectively. Massive blood transfusion was defined as transfusion of $>10$ RBC units in 24 hours.

\section{Statistical analyses}

Data are presented as the median and IQR or as absolute number and percentage. We calculated 95\% $\mathrm{CI}$ for the outcomes. We compared groups using the 
Mann-Whitney $U$-test for continuous data, and the Fisher exact test for categorical data. We studied factors associated with KDIGO stage 3 AKI during the first 5 days of ICU admission, hospital mortality, and 90-day mortality as dependent variables in separate logistic regression models. Variables were selected for the reported models using the enter method. Covariates included in the model predicting KDIGO stage 3 AKI were: pre-ICU hypovolemia, pre-ICU use of colloids, presence of chronic kidney disease, simplified acute physiology score (SAPS) II (without age and renal components, that is, urine output, serum urea, potassium, $\mathrm{HCO} 3$ ), age, gender, $\mathrm{RBC}$ age quartile prior to the highest KDIGO AKI stage and number of RBC units transfused prior to AKI. Patients with KDIGO stage 3 AKI prior to RBC transfusion were excluded from this model. For patients without AKI, we included RBC units transfused within 26 hours from ICU admission, which corresponded to the median time of development of the KDIGO stage 3 AKI. For the models predicting hospital mortality, and separately for 90-day mortality, we generated a propensity score to balance between the patients' probability of receiving older blood (>14 days in Q2 to Q4) and included patients' blood groups, study sites, and the numbers of transfused units in the scoring. To study associations with hospital and 90-day mortality, we used the enter method to add covariates in logistic regression analysis. Covariates in these models were: propensity to receive older blood, age, gender, number of transfused RBC units, age quartiles of transfused RBCs (Q2 to Q4 versus Q1) presence of AKI, severe sepsis, acute physiology and chronic health evaluation (APACHE) II diagnosis group, operative admission, emergency admission, disseminated intravascular coagulopathy (DIC), SAPS II without age points, maximum sequential organ failure assessment (SOFA) score during ICU stay and highest lactate value. We also performed Cox regression analysis of 90-day mortality with the same explanatory variables as we had covariates in logistic regression analysis for the hospital and 90-day mortality. In all analyses a $P$-value less than 0.05 was considered statistically significant. Reported

Table 1 Patient characteristics in quartiles according to oldest red blood cell (RBC) transfusion during the ICU stay

\begin{tabular}{|c|c|c|c|c|c|}
\hline & $\begin{array}{l}\text { Q1 } \\
(n=143)\end{array}$ & $\begin{array}{l}\text { Q2 } \\
(n=156)\end{array}$ & $\begin{array}{l}\text { Q3 } \\
(n=179)\end{array}$ & $\begin{array}{l}\text { Q4 } \\
(n=174)\end{array}$ & $P$-value \\
\hline Age, years & $66(58,76)$ & $66(57,75)$ & $65(54,74)$ & $66(55,75)$ & 0.686 \\
\hline Male gender & $82(57.3 \%)$ & $102(65.4 \%)$ & $114(63.7 \%)$ & $113(64.9 \%)$ & \\
\hline Operative admission & $80(55.9 \%)$ & $85(54.5 \%)$ & $92(51.4 \%)$ & $74(42.5 \%)$ & 0.067 \\
\hline Emergency admission, n/total & $105 / 143(73.4 \%)$ & 114/153 (74.5\%) & 146/174 (83.9\%) & 149/172 (85.6\%) & 0.004 \\
\hline Emergency surgery $<1$ week & $38(26.6 \%)$ & $42(26.9 \%)$ & $58(32.45)$ & $49(28.2 \%)$ & 0.369 \\
\hline Cardiac or vascular surgery & $44(30.8 \%)$ & $56(35.9 \%)$ & $41(22.9 \%)$ & $29(16.7 \%)$ & $<0.001$ \\
\hline Trauma & $9(6.3 \%)$ & $6(3.8 \%)$ & $16(8.9 \%)$ & $13(7.5 \%)$ & 0.303 \\
\hline Severe sepsis & $34(23.8 \%)$ & $50(32.1 \%)$ & 69 (38.5\%) & 69 (39.7\%) & 0.011 \\
\hline $\mathrm{DIC}$ & $5 / 140(3.5 \%)$ & $12 / 151(7.9 \%)$ & $13 / 170(7.6 \%)$ & 16/168 (9.5\%) & 0.239 \\
\hline Acute kidney injury & $52(36.4 \%)$ & $78(50.0 \%)$ & $69(38.5 \%)$ & $69(39.7 \%)$ & 0.029 \\
\hline Renal replacement therapy & $8(5.6 \%)$ & $28(17.9 \%)$ & $34(19.0 \%)$ & $26(14.9 \%)$ & 0.004 \\
\hline SAPS II score & $35(27,44)$ & $36(30,50)$ & $40(28,55)$ & $38(31,53)$ & 0.050 \\
\hline Maximum SOFA score & $8(6,10)$ & $9(6,11)$ & $9(6,11)$ & $9(6,11)^{a}$ & 0.031 \\
\hline Mechanical ventilaiton & $110(76.9 \%)$ & $132(84.6 \%)$ & 149 (83.2\%) & $132(75.9 \%)$ & 0.112 \\
\hline Vasoactive use & $111(77.6 \%)$ & $124(79.5 \%)$ & $142(79.3 \%)$ & $130(74.7 \%)^{\mathrm{a}}$ & 0.751 \\
\hline Lactate, $\mathrm{mmol} / \mathrm{L}^{\mathrm{b}}$ & $1.96(1.20,3.40)$ & $2.80(1.50,3.40)$ & $2.40(1.44,4.60)$ & $2.54(1.50,4.77)$ & 0.009 \\
\hline Age of all RBCs, days & $11(9,12)$ & $14(11,15)$ & $17(13,20)$ & $17(12,26)$ & $<0.001$ \\
\hline Maximum age of RBCs, days & $12(10,13)$ & $15(14,16)$ & $21(19,22)$ & $29(27,32)$ & $<0.001$ \\
\hline Transfused units, $\mathrm{n}$ & $2(2,4)$ & $3(2,5)$ & $3(2,6)$ & $4(2,8)$ & 0.001 \\
\hline RBC units over 14 days old, $n$ & 0 & $2(1,3)$ & $2(1,4)$ & $3(2,6)$ & $<0.001$ \\
\hline Massive transfusion pre-ICUc & $8(5.6 \%)$ & $9(5.8 \%)$ & $7(3.9 \%)$ & $15(8.6 \%)$ & 0.312 \\
\hline Admission hemoglobin, $g / L^{d}$ & $100(90,112)$ & $97(88,107)$ & $97(88,110)]$ & $98(85,113)$ & 0.544 \\
\hline
\end{tabular}

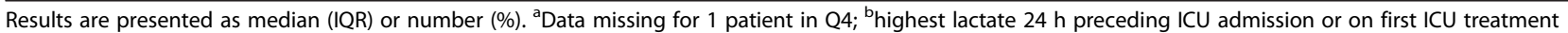

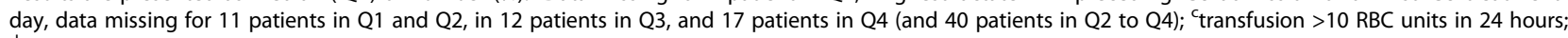
${ }^{d}$ data missing for 11 patients in Q1, 19 in Q2, 27 in Q3, 20 in Q4 (and 86 patients in Q2-4); n, number; RBC, red blood cell; DIC, disseminated intravascular coagulopathy; SAPS II, simplified acute physiology score; SOFA, sequential organ failure assessment. 
Table 2 Incidence of AKI according to KDIGO staging in transfused patients according to quartiles of oldest red blood cells transfused

\begin{tabular}{llll}
\hline & Quartile 1 $(\mathbf{n}=\mathbf{1 4 3})$ & Quartiles 2 to 4 $(\mathbf{n}=\mathbf{5 0 9 )}$ & $\boldsymbol{P}$-value \\
\hline No AKI & $63.6 \%(55.8,71.5)$ & $49.5 \%(45.2,53.9)$ & 0.003 \\
Stage 1 & $19.6 \%(13.1,26.1)$ & $19.6 \%(16.2,23.1)$ & $>0.999$ \\
Stage 2 & $5.6 \%(1.8,9.4)$ & $9.4 \%(6.9,12.0)$ & 0.177 \\
Stage 3 & $11.2 \%(6.0,16.4)$ & $21.4 \%(17.9,25.0)$ & 0.006 \\
RRT & $5.6 \%(1.8,9.4)$ & $17.3 \%(14.0,20.6)$ & $<0.001$ \\
\hline
\end{tabular}

Results are presented as percentage of patients $(95 \% \mathrm{Cl})$. AKI, acute kidney injury; KDIGO, Kidney Disease: Improving Global Outcomes; RRT, renal replacement therapy.

$P$-values were not corrected for possible multiple testing. Data were analyzed with SPSS version 19 (SPSS, Chicago, IL, USA).

\section{Results}

Of the 1,811 eligible patients, 665 received at least one RBC transfusion during the ICU stay. In 13 patients, however, the age of RBC units could not be confirmed and they were excluded from the analysis leaving 652 patients $(36.6 \%)$ in the transfused patient population. During ICU treatment, the transfused patients received 3 (2 to 6) units of RBCs. The patient characteristics according to transfusion status are presented in Additional file 1: Table S1. The median (IQR) age of all RBC units transfused was 14 (11-19) days and the median age of the oldest RBC unit transfused was 18 (14 to 25) days. Of all 3,325 transfusions, 2,334 (70.2\%) were given during the first 72 hours of ICU treatment, and the median time from ICU admission to the administration of the oldest RBC unit was 22 (0.2 to 70.0) hours. The times for ICU admission, AKI and RBC transfusions are presented in Additional file 1: Table S2. The patient characteristics according to the quartiles of the oldest RBCs are presented in Table 1 .

The incidence of different stages of AKI and administration of RRT, according to quartiles of the oldest RBC unit, are presented in Table 2. In the logistic regression model, only the SAPS II score (without age and renal components) and number of RBCs transfused prior to AKI were independent risk factors for KDIGO stage 3 AKI (Table 3). The number of patients with renal nonrecovery was inadequate for analysis as a dependent variable by logistic regression (Table 4).

The ICU length of stay, renal non-recovery, hospital and 90-day mortality rates are presented in Table 4. On logistic regression, patients in $\mathrm{RBC}$ age quartiles 2 to 4 had increased risk of hospital mortality compared to patients in the freshest quartile. Age, SAPS II without age points and maximum SOFA score were also associated with increased risk of hospital mortality (Additional file 1: Table S3). In a separate model for 90-day mortality, age, number of transfused units, SAPS II without age points and maximum SOFA score were significant predictors, whereas the age of RBCs was not (Table 5). The hazard ratios from Cox regression analysis are presented in Additional file 1: Table S4. The hospital and 90-day mortality rates in transfused patients according to quartiles of the oldest transfused RBCs are presented in Figures 1 and 2 .

\section{Discussion}

In this large, observational multicenter study, we found that transfusion of older RBCs was independently associated with an increased risk of hospital mortality, but not 90-day mortality, or the development of KDIGO stage 3 AKI. The number of transfused RBC units, however, was independently associated with 90-day mortality.

Evidence on the impact of storage lesions of RBCs in critically ill patients is accumulating. The evidence for a deleterious effect arises mostly from observational studies. The only large RCT has been conducted in premature infants, and in this patient group, there was no morbidity or mortality benefit of fresher (less than 7 days) RBC transfusion compared to standard care [11]. The RCTs including adult patients have been smaller, with only 17 to 100 patients, aiming to test the feasibility of study logistics, or with surrogate variables as study endpoints $[8-10,18]$. Large RCTs are underway, but the

Table 3 Odds ratios with $95 \% \mathrm{Cl}$ from logistic regression analysis of KDIGO stage 3 acute kidney injury

\begin{tabular}{|c|c|c|c|c|}
\hline Variable & Odds ratio & $95 \% \mathrm{Cl}$ lower & 95\% Cl upper & $P$-value \\
\hline Age, years & 1.005 & 0.984 & 1.026 & 0.628 \\
\hline Female gender & 0.586 & 0.306 & 1.124 & 0.108 \\
\hline Chronic kidney disease & 1.924 & 0.737 & 5.021 & 0.181 \\
\hline SAPS II score without points for age and renal componenents, points & 1.060 & 1.037 & 1.084 & $<0.001$ \\
\hline Pre-ICU colloids & 1.134 & 0.615 & 2.093 & 0.686 \\
\hline Pre-ICU hypovolemia & 1.177 & 0.625 & 2.219 & 0.613 \\
\hline RBC, Q2 to Q4 versus Q1 & 1.066 & 0.507 & 2.238 & 0.867 \\
\hline Units transfused pre-AKI, number & 1.076 & 1.019 & 1.135 & 0.008 \\
\hline
\end{tabular}

In total, 404 patients were included in the model. Hosmer-Lemeshow Chi-square $9.390 P=0.310$. Q1 denotes the first and freshest oldest RBC unit quartile, Q2 to Q4 denotes the second to the fourth quartile. SAPS II, simplified acute physiology score, RBC, red blood cell; AKI, acute kidney injury. 
Table 4 Patient outcomes (quartiles according to the oldest red blood cells transfused)

\begin{tabular}{llll}
\hline & $\begin{array}{l}\text { Quartile 1 } \\
(\mathbf{n}=\mathbf{1 4 3})\end{array}$ & $\begin{array}{l}\text { Quartiles 2 to 4 } \\
(\mathbf{n}=\mathbf{5 0 9})\end{array}$ & $\begin{array}{l}\boldsymbol{P} \text { - } \\
\text { value }\end{array}$ \\
\hline ICU length of stay, days & $2.8(1.6,4.8)$ & $4.2(1.9,8.7)$ & $<0.001$ \\
Renal non-recoveryt & $1.4 \%(0.4,5.0)$ & $1.2 \%(0.5,2.6)$ & 0.689 \\
Hospital mortality & $10.5 \%(5.5,15.5)$ & $20.8 \%(17.3,24.4)$ & 0.005 \\
90-day mortality & $20.3 \%(13.7,26.9)$ & $29.9 \%(25.9,33.8)$ & 0.026 \\
\hline
\end{tabular}

The results are presented as median and IQR or as percentage with $95 \%$ confidence interval. Renal non-recovery is defined as dialysis dependence at 90 days.

results will be available only after several years $[19,20]$, leaving clinicians uncertain with regard to the importance of age of RBCs.

RBC transfusions have also been associated with an increased risk of renal failure [21]. Transfusion of older RBCs has been associated with increased risk of renal failure in some studies [22,23], whereas in others no independent association of RBC age with AKI was found [21]. The power of our study was inadequate to study the association between age of blood and renal nonrecovery. In the model predicting KDIGO stage 3, only scores on SAPS II without age points, and number of $\mathrm{RBCs}$ transfused, were independent predictors of AKI, whereas the age of RBCs was not. The prediction of KDIGO stage 3 AKI was also relatively inaccurate in this patient population as the median time from ICU admission to KDIGO stage 3 AKI was only 26 hours, and accordingly only a small proportion of RBC's had been transfused prior to AKI.
Most observational studies on the effects of age of transfused RBCs on patient morbidity and mortality have been conducted in trauma and cardiac surgery patients [7]. Although these patients are often treated in the ICU, they have lower overall mortality as a group, and accordingly are not representative of the general critically ill patient population $[24,25]$. Of the two observational studies that have been conducted in unselected critically ill patients $[17,26]$, one has been published only as an abstract [26]. In the Australian and New Zealand Intensive Care Society (ANZICS) study, the results were in line with our findings, as the hospital mortality increased with increasing age of the oldest RBC unit [17]. The long-term mortality was not, however, reported in that study. In a meta-analysis combining patients with various conditions (cardiac surgery, trauma and general hospitalized patients), transfusion of older RBC units was associated with increased mortality [7]. The highest impact on the result comes, however, from a retrospective study of 387,130 hospitalized patients, reporting one-week mortality. Critically ill patients represented less than $1 \%$ of the total number of patients in this meta-analysis [7].

There are several methods of producing RBC units from donated blood $[13,27]$. The differences in $\mathrm{RBC}$ production methods have an effect on the degree and magnitude of storage lesions over time, leading to variations in the recommended storage times for $\mathrm{RBC}$ units [27]. Interestingly, studies conducted in North America consistently report an increased risk of adverse endpoints with increased RBC storage age [28]. The results of studies conducted

Table 5 Odds ratios and $95 \% \mathrm{Cl}$ from logistic regression analysis of 90 -day mortality

\begin{tabular}{|c|c|c|c|c|}
\hline Variable & $\begin{array}{l}\text { Odds } \\
\text { ratio }\end{array}$ & $\begin{array}{l}95 \% \mathrm{Cl} \\
\text { lower }\end{array}$ & $\begin{array}{l}95 \% \mathrm{Cl} \\
\text { upper }\end{array}$ & $\begin{array}{l}P \text { - } \\
\text { value }\end{array}$ \\
\hline Age & 1.043 & 1.025 & 1.061 & $<0.001$ \\
\hline Propensity score for receiving $>14$ day-old RBCs & 0.083 & 0.004 & 1.791 & 0.112 \\
\hline Transfused units, number & 1.057 & 1.010 & 1.106 & 0.017 \\
\hline Acute kidney injury & 0.774 & 0.472 & 1.271 & 0.312 \\
\hline Severe sepsis & 0.785 & 0.478 & 1.288 & 0.338 \\
\hline RBC age Q2 to Q4 versus Q1 & 1.448 & 0.822 & 2.552 & 0.200 \\
\hline APACHE II diagnosis group & 1.000 & 0.998 & 1.001 & 0.546 \\
\hline Operative admission & 1.342 & 0.797 & 2.259 & 0.268 \\
\hline Emergency admission & 1.607 & 0.628 & 4.111 & 0.322 \\
\hline DIC & 1.537 & 0.633 & 3.731 & 0.342 \\
\hline SAPS II score without age points & 1.031 & 1.011 & 1.051 & 0.002 \\
\hline SOFA score, maximum during ICU stay & 1.219 & 1.114 & 1.333 & $<0.001$ \\
\hline Highest lactate & 0.997 & 0.939 & 1.058 & 0.913 \\
\hline Female gender & 0.785 & 0.495 & 1.244 & 0.303 \\
\hline
\end{tabular}

Included patients 571 (132 in Q1 and 468 in Q2 to Q4). Hosmer-Lemeshow Chi-square 5.407, $P=0.713$. RBC, red blood cell; Q, quartile; APACHE, acute physiology and chronic health evaluation; DIC, disseminated intravascular coagulopathy; SAPS, simplified acute physiology score; SOFA, sequential organ failure assessment. 


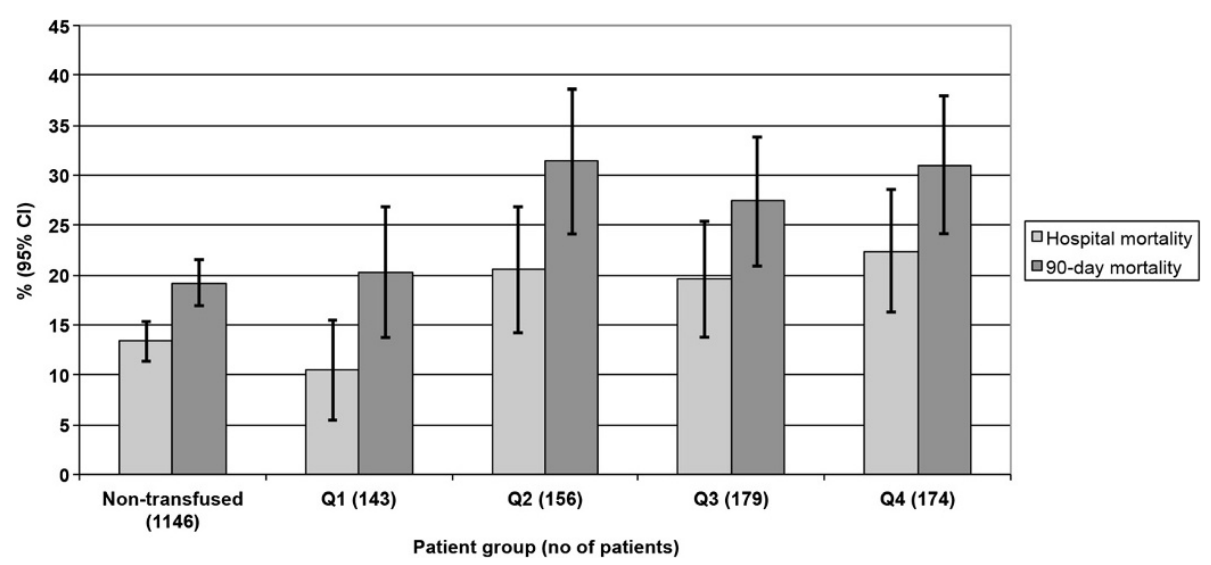

Figure 1 Crude hospital and 90-day mortality in non-transfused and transfused patients according to quartiles (Q) of the oldest red blood cell (RBC) unit.

elsewhere show more variation $[17,28]$. Some of the differences in study results are suggested to be the result of a different production process leading to differences in storage lesions in RBC units [28].

This is the first study to describe the incidence of AKI and long-term mortality in critically ill patients transfused with RBCs of varying storage times. In our study, AKI was described by the latest recommended staging by KDIGO [15]. As presented in Table 2, there were seemingly more AKI and more stage $3 \mathrm{AKI}$ in patients in the RBC age quartiles 2 to 4 . However, when appropriate adjustments in multivariable analysis were performed, the age of transfused RBCs was not associated with the development of AKI stage 3. This implies that the incidence of KDIGO stage 3 AKI is not increased by transfusion of older RBCs. Hospital and 90-day crude mortality rates

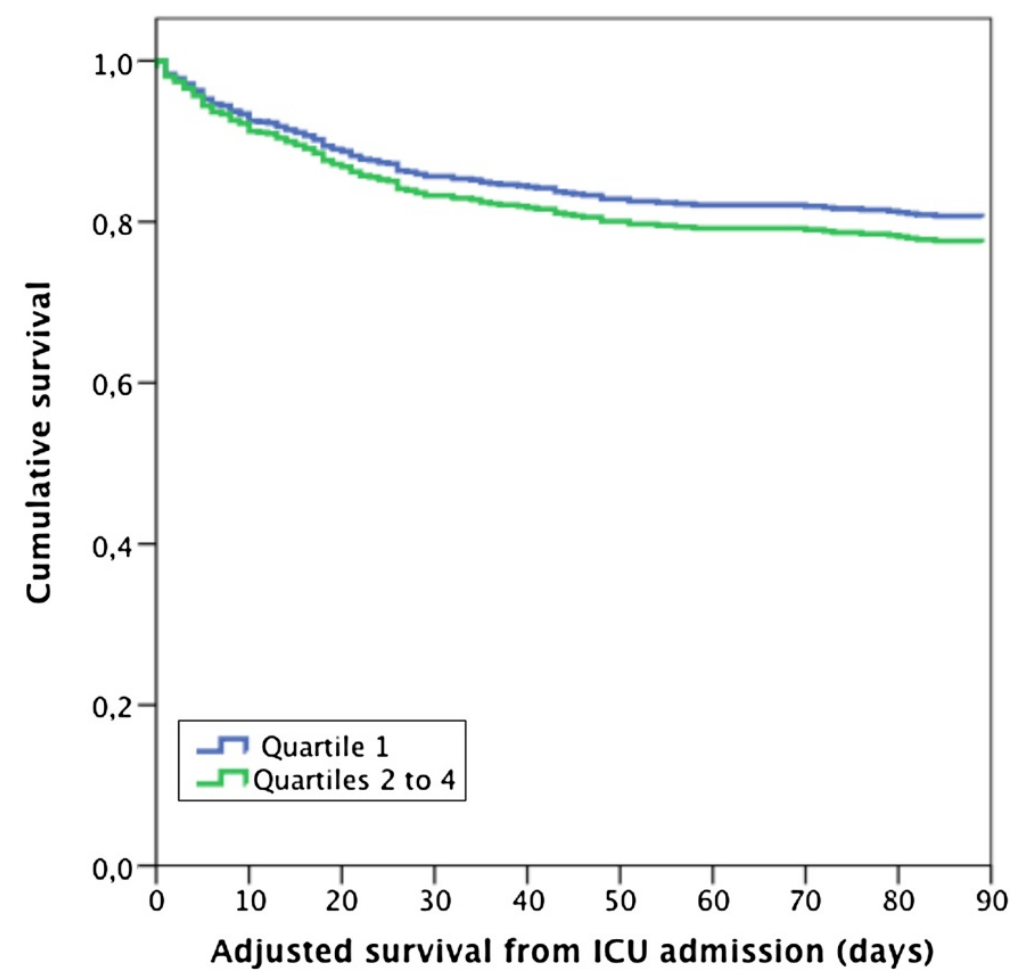

Figure 2 Kaplan-Meier curve (adjusted for baseline variables) for non-transfused and transfused patients according to quartiles (Q) of the oldest red blood cell (RBC) unit. 
were significantly different between $\mathrm{RBC}$ age quartiles 1 versus quartiles 2 to 4 . Here again, the adjustment for other variables showed that the transfusion of fresher RBCs was associated with hospital mortality but not 90day mortality. The association between transfusion of aged RBCs and hospital mortality has been shown previously, but this is the first study to investigate the association with long-term mortality.

In non-randomized studies, there are frequently baseline differences between patient populations. In baseline variables, there are many differences in patient characteristics across quartiles of $\mathrm{RBC}$ age with increasing severity towards Q4. Previously, increased number of $\mathrm{RBC}$ transfusions has been associated with both sicker patients and increased risk of having older RBCs [29]. Adjusting for these differences in multivariable analysis translates findings more reliably, however, there is still room for residual confounders. This underlines the need for an RCT with sufficient power and clinically relevant endpoints to either confirm or refute the possible negative effects of older RBCs transfused to critically ill patients.

Our study has some limitations. First, the RBC data prior to ICU admission was not available, except for the information on massive blood transfusions ( $>10$ units of $\mathrm{RBCs}$ in 24 hours) prior to admission. As individual $\mathrm{RBC}$-unit information was not available, the age of RBCs in these pre-ICU transfusions remains unknown. Second, we did not collect the information on the use of other blood products, as the primary study was targeted to evaluate the incidence and prognosis of AKI in critically ill patients. Third, renal non-recovery was rare, and accordingly, the study was not powered to evaluate the possible associations of risk factors with poor renal recovery. Fourth, due to the observational design of this study, the transfused patients were different between quartiles of oldest RBCs transfused and those who were transfused versus non-transfused. In the analysis without adjustment for baseline differences, there was an increase in the incidence of AKI, and hospital and 90-day mortality (Tables 2 and 4). However, when adjusted for the baseline differences in multivariable analysis, the age of the oldest RBC unit was independently associated with hospital mortality only, but not with KDIGO stage 3 AKI or 90-day mortality. As we could adjust only for the variables that were collected in the study, residual confounders cannot be excluded.

\section{Conclusions}

In this prospective observational study we were able to confirm the independent association between transfusion of older RBCs and increased risk of hospital mortality, but did not detect an independent association with 90-day mortality or the development of KDIGO stage 3
AKI. However, the number of transfused RBC units was an independent predictor of 90-day mortality in unselected critically ill patients. A large-scale multicenter RCT is needed to evaluate the possible negative effect of older RBCs in critically ill patients.

\section{Key messages}

- $36.6 \%$ of critically ill patients were transfused during the ICU stay.

- Transfused patients received a median of 3 units (IQR 2 to 6) of RBCs.

- $70.2 \%$ of all transfusions were given within 72 hours of ICU admission.

- The age of transfused RBCs was independently associated with hospital mortality but not with 90-day mortality or KDIGO stage 3 AKI.

- The number of transfused RBCs was an independent risk factor for 90-day mortality.

\section{Additional file}

Additional file 1: Table S1. Characteristics of non-transfused and transfused patients. Table S2: Times for ICU admission and AKI (acute kidney injury). Table S3: Odds ratios with 95\% Cl from logistic regression analysis of hospital mortality. Table S4: Cox regression analysis for 90-day mortality (enter method).

\section{Abbreviations}

AKl: Acute kidney injury; APACHE: Acute physiology and chronic health evaluation; DIC: Disseminated intravascular coagulopathy; FINNAKI: FINNish Acute Kidney Injury; KDIGO: Kidney disease: improving global outcomes; Q1: Lowest quartile; RBC: Red blood cell; RCT: Randomized controlled trial; RRT: Renal replacement therapy; SAPS II: Simplified acute physiology score; SOFA: Sequential organ failure assessment.

\section{Competing interests}

The authors declare no competing interests on this study.

\section{Authors' contributions}

KMK: contribution to study conception and design, financing, acquisition of data, analysis and interpretation of data, drafting the article and responsible for the final output of the publication. SV: contribution to study conception and design, acquisition of data, statistical analysis and interpretation of data, drafting the article, intellectual contribution to study result analysis and critical revision of the manuscript. VP: substantial contributions to conception and design, financing, acquisition of data, analysis and interpretation of data, critical revision for important intellectual content of the manuscript. RB: Intellectual contribution to study result analysis and critical revision of the manuscript. JT: acquisition of data, analysis and interpretation of data, critical revision for important intellectual content of the manuscript. JC: analysis and interpretation of data, critical revision for important intellectual content of the manuscript. TK: analysis and interpretation of data, critical revision for important intellectual content of the manuscript. AK: acquisition of data, drafting the article, intellectual contribution to study result analysis and critical revision of the manuscript. MR: acquisition of data, intellectual contribution to study result analysis and critical revision of the manuscript. JK: contribution to study conception and design, acquisition of data, statistical analysis and interpretation of data, drafting the article, intellectual contribution to study result analysis and critical revision of the manuscript. AU: contribution to study conception and design, acquisition and interpretation of data, drafting the article, intellectual contribution to study result analysis and critical revision of the manuscript. The FINNAKI study 
group: contribution to study conception and design, financing, acquisition of data. All authors have approved the final version of the manuscript.

\section{Acknowledgements}

The FINNAKI Study Group comprises: Central Finland Central Hospital: Raili Laru-Sompa, Anni Pulkkinen, Minna Saarelainen, Mikko Reilama, Sinikka Tolmunen, Ulla Rantalainen, Marja Miettinen. East Savo Central Hospital: Markku Suvela, Katrine Pesola, Pekka Saastamoinen, Sirpa Kauppinen. Helsinki University Central Hospital: Ville Pettilä, Kirsi-Maija Kaukonen, Anna-Maija Korhonen, Sara Nisula, Suvi Vaara, Raili Suojaranta-Ylinen, Leena Mildh, Mikko Haapio, Laura Nurminen, Sari Sutinen, Leena Pettilä, Helinä Laitinen, Heidi Syrjä, Kirsi Henttonen, Elina Lappi, Hillevi Boman. Jorvi Central Hospital: Tero Varpula, Päivi Porkka, Mirka Sivula Mira Rahkonen, Anne Tsurkka, Taina Nieminen, Niina Prittinen. Kanta-Häme Central hospital: Ari Alaspää, Ville Salanto, Hanna Juntunen, Teija Sanisalo. Kuopio University Hospital: Ilkka Parviainen, Ari Uusaro, Esko Ruokonen, Stepani Bendel, Niina Rissanen, Maarit Lång, Sari Rahikainen, Saija Rissanen, Merja Ahonen, Elina Halonen, Eija Vaskelainen. Lapland Central Hospital: Meri Poukkanen, Esa Lintula, Sirpa Suominen. Länsi-Pohja Central Hospital: Jorma Heikkinen, Timo Lavander, Kirsi Heinonen, Anne-Mari Juopperi. Middle Ostrobothnia Central Hospital: Tadeusz Kaminski, Fiia Gäddnäs, Tuija Kuusela, Jane Roiko. North Karelia Central Hospital: Sari Karlsson, Matti Reinikainen, Tero Surakka, Helena Jyrkönen, Tanja Eiserbeck, Jaana Kallinen. Satakunta Hospital district: Vesa Lund, Päivi Tuominen, Pauliina Perkola, Riikka Tuominen, Marika Hietaranta, Satu Johansson. South Karelia Central Hospital: Seppo Hovilehto, Anne Kirsi, Pekka Tiainen, Tuija Myllärinen, Pirjo Leino, Anne Toropainen. Tampere University Hospital: Anne Kuitunen, Ilona Leppänen, Markus Levoranta, Sanna Hoppu, Jukka Sauranen, Jyrki Tenhunen, Atte Kukkurainen, Samuli Kortelainen, Simo Varila. Turku University Hospital: Outi Inkinen, Niina Koivuviita, Jutta Kotamäki, Anu Laine. Oulu University Hospital: Tero AlaKokko, Jouko Laurila, Sinikka Sälkiö. Vaasa Central Hospital: Simo-Pekka Koivisto, Raku Hautamäki, Maria Skinnar.

\section{Funding}

KMK has received a grant for a Clinical Researcher career from the Academy of Finland. Clinical Research funding (EVO) TYH 2010109/2011210 and T102010070 from Helsinki University Hospital, and a grant from the Finnish Society of Intensive Care, and a grant from the Academy of Finland, and the Juselius Foundation. RB and JC are supported by NHMRC Practitioner Fellowship grants.

\section{Author details}

${ }^{1}$ ANZIC Research Centre, Department of Epidemiology and Preventative Medicine, School of Public Health \& Preventive Medicine, Monash University, 99 Commercial Road, Melbourne, VIC 3004, Australia. ${ }^{2}$ Intensive Care Unit, Helsinki University Central Hospital, Helsinki, Finland. ${ }^{3}$ Department of Clinical Sciences, University of Helsinki, Helsinki, Finland. ${ }^{4}$ Finnish Red Cross Blood Service, Helsinki, Finland. Intensive Care Unit, Tampere University Hospital, Tampere, Finland. ${ }^{6}$ Intensive Care Unit, North Karelia Central Hospital, Joensuu, Finland. '7Department of Anesthesiology, Division of Intensive Care, Oulu University Hospital, Oulu, Finland. ${ }^{8}$ Intensive Care Unit, Kuopio University Hospital, Kuopio, Finland.

Received: 18 December 2012 Accepted: 8 August 2013 Published: 4 October 2013

\section{References}

1. Vincent JL, Baron J-F, Reinhart K, Gattinoni L, Thijs L, Webb A, MeierHellmann A, Nollet G, Peres-Bota D, Investigators ABC: Anemia and blood transfusion in critically ill patients. JAMA 2002, 288:1499-1507.

2. Corwin HL, Gettinger A, Pearl RG, Fink MP, Levy MM, Abraham E, Maclntyre NR, Shabot MM, Duh M-S, Shapiro MJ: The CRIT Study: Anemia and blood transfusion in the critically ill-current clinical practice in the United States. Crit Care Med 2004, 32:39-52.

3. Hebert PC, Wells G, Blajchman MA, Marshall J, Martin C, Pagliarello G, Tweeddale M, Schweitzer I, Yetisir E: A multicenter, randomized, controlled clinical trial of transfusion requirements in critical care. Transfusion requirements in critical care investigators, Canadian critical care trials group. N Engl J Med 1999, 340:409-417.

4. Park DW, Chun BC, Kwon SS, Yoon YK, Choi WS, Sohn JW, Peck KR, Kim YS, Choi YH, Choi JY, Kim SI, Eom JS, Kim HY, Cheong HJ, Song YG, Choi HJ,
Kim JM, Kim MJ: Red blood cell transfusions are associated with lower mortality in patients with severe sepsis and septic shock: a propensitymatched analysis. Crit Care Med 2012, 40(12):3140-3145.

5. Parsons EC, Hough CL, Seymour CW, Cooke CR, Rubenfeld GD, Watkins TR: Red blood cell transfusion and outcomes in patients with acute lung injury, sepsis and shock. Crit Care 2011, 15:R221.

6. Tinmouth A, Fergusson D, Yee IC, Hebert PC: Clinical consequences of red cell storage in the critically ill. Transfusion 2006, 46:2014-2027.

7. Wang D, Sun J, Solomon SB, Klein HG, Natanson C: Transfusion of older stored blood and risk of death: a meta-analysis. Transfusion 2012, 52:1184-1195.

8. Schulman Cl, Nathe K, Brown M, Cohn SM: Impact of age of transfused blood in the trauma patient. J Trauma 2002, 52:1224-1225.

9. Hebert PC, Chin-Yee I, Fergusson D, Blajchman M, Martineau R, Clinch J, Olberg B: A pilot trial evaluating the clinical effects of prolonged storage of red cells. Anesth Anal 2005, 100:1433-1438.

10. Kor DJ, Kashyap R, Weiskopf RB, Wilson GA, van Buskirk CM, Winters JL, Malinchoc M, Hubmayr RD, Gajic O: Fresh red blood cell transfusion and short-term pulmonary, immunologic, and coagulation status: a randomized clinical trial. Am J Respir Crit Care Med 2012, 185:842-850.

11. Fergusson DA, Hebert $P$, Hogan DL, LeBel L, Rouvinez-Bouali N, Smyth JA, Sankaran K, Tinmouth A, Blajchman MA, Kovacs L, Lachance C, Lee S, Walker CR, Hutton B, Ducharme R, Balchin K, Ramsay T, Ford JC, Kakadekar A, Ramesh K, Shapiro S: Effect of fresh red blood cell transfusions on clinical outcomes in premature, very low-birth-weight infants: the ARIPI randomized trial. JAMA 2012, 308(14):1443-1451.

12. Nisula S, Kaukonen KM, Vaara S, Korhonen A, Poukkanen M, Karlsson S, Haapio M, Inkinen O, Parviainen I, Suojaranta-Ylinen R, Laurila JJ, Tenhunen J, Reinikainen M, Ala-Kokko T, Ruokonen E, Kuitunen A, Pettila V, FINNAKI Study Group: Incidence, risk factors and 90-day mortality of patients with acute kidney injury in Finnish intensive care units: the FINNAKI study. Intensive Care Med 2012, (in press).

13. European Directorate for the Quality of Medicines \& HealthCare: Guide to the preparation, use and quality assurance of blood components. 16th edition. 2010, ISSN/ISBN: 978-92-871-7637-0.

14. Bone RC, Balk RA, Cerra FB, Dellinger RP, Fein AM, Knaus WA, Schein RM, Sibbald WJ: Definitions for sepsis and organ failure and guidelines for the use of innovative therapies in sepsis, The ACCP/ SCCM Consensus Conference Committee. American College of Chest Physicians/Society of Critical Care Medicine. Chest 1992, 101:1644-1655.

15. Acute Kidney Injury Work Group: Kidney Disease: improving global outcomes (KDIGO) acute kidney injury work group. KDIGO clinical practice guideline for acute kidney injury. Kidney Int 2012, Suppl 2:1-138

16. Bellomo R, Ronco C, Kellum JA, Mehta RL, Palevsky P: Acute renal failure definition, outcome measures, animal models, fluid therapy and information technology needs: the second international consensus conference of the acute dialysis quality initiative (ADQI) group. Crit Care 2004, 8:R204-R212.

17. Pettila V, Westbrook AJ, Nichol AD, Bailey MJ, Wood EM, Syres G, Phillips LE, Street A, French C, Murray L, Orford N, Santamaria JD, Bellomo R, Cooper DJ: Age of red blood cells and mortality in the critically ill. Crit Care 2011, 15(2):R116.

18. Aubron C, Syres G, Nichol A, Bailey M, Board J, Magrin G, Murray L, Presneill J, Sutton J, Vallance S, Morrison S, Bellomo R, Cooper DJ: A pilot feasibility trial of allocation of freshest available red blood cells versus standard care in critically ill patients. Transfusion 2012, 52(6):1196-1202.

19. Lacroix J, Hebert P, Fergusson D, Tinmouth A, Blajchman MA, Callum J, Cook D, Marshall JC, Mclntyre L, Turgeon AF, Able study group: The Age of Blood Evaluation (ABLE) randomized controlled trial: study design. Transfus Med Rev 2011, 25(3):197-205.

20. Cooper DJ: Standard issue transfusion versus fresher red blood cell use in intensive care- a randomised controlled trial (TRANSFUSE). 2012: [http://www.clinicaltrials.gov/ct2/show/NCT01638416?term=age+of+red+ blood+cell\&rank=2].

21. Yap CH, Lau L, Krishnaswamy M, Gaskell M, Yii M: Age of transfused red cells and early outcomes after cardiac surgery. Ann Thorac Surg 2008, 86:554-559.

22. Koch CG, Li L, Sessler DI, Figueroa P, Hoeltge GA, Mihaljevic T, Blackstone $\mathrm{EH}$ : Duration of red-cell storage and complications after cardiac surgery. N Engl J Med 2008, 358:1229-1239. 
23. Weinberg JA, McGwin G Jr, Marques MB, Cherry SA 3rd, Reiff DA, Kerby JD, Rue LW 3rd: Transfusions in the less severely injured: does age of transfused blood affect outcomes? J Trauma 2008, 65:794-798.

24. Shannon FL, Fazzalari FL, Theurer PF, Bell GF, Sutcliffe KM, Prager RL: Michigan Society of T, Cardiovascular S: a method to evaluate cardiac surgery mortality: phase of care mortality analysis. Ann Thorac Surg 2012, 93:36-43.

25. Reinikainen $M$, Uusaro A, Ruokonen $E$, Niskanen M: Excess mortality in winter in Finnish intensive care. Acta Anaesthesiol Scand 2006, 50:706-711.

26. van Buskirk CM, Kashyap R, Thakur SJ, Murray DL, Bryant SC, Winters JL, Stubbs JR, Gajic O: Red blood cell storage age has no impact on clinical outcome in critically ill patients. Transfusion 2009, 49:S18010D.

27. Hess JR: Biomedical excellence for safer transfusion C: scientific problems in the regulation of red blood cell products. Transfusion 2012, 52:1827-1835.

28. van de Watering $L$ : Red cell storage and prognosis. Vox sanguinis 2011, 100:36-45.

29. van de Watering L: Pitfalls in the current published observational literature on the effects of red blood cell storage. Transfusion 2011, 51:1847-1854

doi:10.1186/cc13045

Cite this article as: Kaukonen et al: Age of red blood cells and outcome in acute kidney injury. Critical Care 2013 17:R222.

\section{Submit your next manuscript to BioMed Central and take full advantage of:}

- Convenient online submission

- Thorough peer review

- No space constraints or color figure charges

- Immediate publication on acceptance

- Inclusion in PubMed, CAS, Scopus and Google Scholar

- Research which is freely available for redistribution 